\title{
Liliaceae endémicas del Perú
}

Blanca León ${ }^{1,2}$

${ }^{1}$ Museo de Historia Natural, Av. Arenales 1256, Aptdo. 14-0434, Lima 14, Perú

2 Plant Resources Center, University of Texas at Austin, Austin TX 78712 EE.UU.

blanca.leon@mail.utexas.edu

\section{Resumen}

La familia Liliaceae es reconocida en el Perú con 15 géneros (excepto Alstroemeria y Bomarea) y aproximadamente 29 especies (Brako \& Zarucchi, 1993; Ulloa Ulloa et al., 2004), todas ellas hierbas. Esta familia incluye tres géneros endémicos, Diamena, Diora y Trichlora. En este trabajo reconocemos 11 especies endémicas en cinco géneros. Se asignó las categorías de amenaza de la UICN a seis especies. La mitad de los endemismos es conocido solamente de una localidad. Los taxones endémicos ocupan las regiones del Desierto Semicálido Costero y Mesoandina, entre los 600 y 3600 m de altitud. Solamente una especie está representada en un área natural protegida.

Palabras claves: Liliaceae, Diamena, Diora, Trichlora, Perú, endemismo, plantas endémicas.

\section{Abstract}

The Liliaceae are represented in Peru by 15 genera (excluding Alstroemeria y Bomarea) and approximately 29 species of herbaceous plants (Brako \& Zarucchi, 1993; Ulloa Ulloa et al., 2004). The family includes three genera endemic to Peru: Diamena, Diora and Trichlora. Here we recognize 11 endemic species in five genera. We assigned IUCN threat categories to six species. Half of the endemic species are known from a single locality. Endemic taxa occupy the Dry Subtropical Coastal, and Mesoandean regions, between 600 and 3600 m elevation. Only one endemic species has been found to date in a Peruvian protected area.

Keywords: Liliaceae, Diamena, Diora, Trichlora, Peru, endemism, endemic plants.

\section{Anthericum collinum Ravenna}

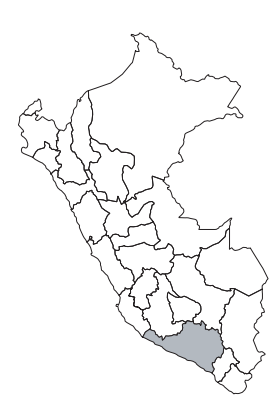

NE

Publicación: Onira 1(3): 26., nom. Illeg. No Poelln. (1942) 1988.

Colección tipo: P.F. Ravenna 3329

Herbarios: Hb. Ravenna, K.

Nombre común: Desconocido,

Registro departamental: AR.

Regiones Ecológicas: DST; altitud desconocida.

SINANPE: Sin registro.

Herbarios peruanos: Ninguno.

Observaciones: Esta especie fue descrita por Ravenna (1988a), pero el nombre empleado había sido ya propuesto por Poellnitz en 1942. El ejemplar que Ravenna empleó para describir esta especie, provenía de material cultivado, recolectado en Arequipa.

\section{Anthericum glareosum Ravenna}

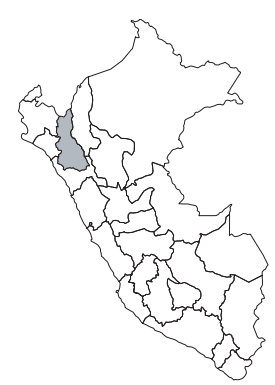

Publicación: Onira 1(3): 29-30. 1988. Colección tipo: A. López M. s.n.

Herbarios: Hb. Ravenna, K.

Nombre común: Desconocido.

Registro departamental: CA.

Regiones Ecológicas: MA; 2550—2850 m.

SINANPE: Sin registro.

Herbarios peruanos: CPUN (4).

Observaciones: Hierba conocida del norte del país. Esta especie aparentemente está relacionada con Anthericum weberbaueri. No ha sido posible evaluarla, ni asignarle una categoría.

\section{Anthericum glaucum Ruiz \& Pav.}

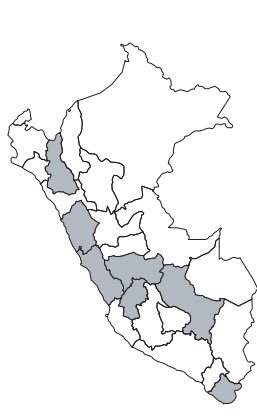

LC

Publicación: Flora 3: 68. 1802.

Colección tipo: H. Ruiz \& J. Pavón s.n.

Herbarios:

Nombre común: Desconocido.

Registro departamental: AN, CA, CU, HV, JU, LI, TA.

Regiones Ecológicas: DST, MDE, MA; 600-3600 m.

SINANPE: Sin registro.

Herbarios peruanos: CPUN (4), HAO (1), USM (11).

Observaciones: Esta especie es conocida de varias localidades, ubicadas en la vertiente occidental y en valles interandinos. Probablemente se encuentre en la flora de países vecinos.

\section{Anthericum ticsanianum Ravenna}

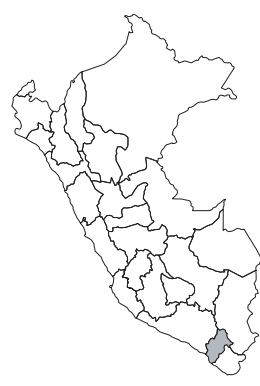

Publicación: Onira 1(3): 28. 1988.

Colección tipo: P.F. Ravenna 3162

Herbarios: Hb. Ravenna, K.

Nombre común: Desconocido.

Registro departamental: MO.

Regiones Ecológicas: MA; altitud desconocida.

SINANPE: Sin registro.

Herbarios peruanos: Ninguno.

Observaciones: Planta bulbígera conocida de la colección tipo, una planta en cultivo, originalmente recolectada en el sur occidente del país. No ha sido posible evaluarla, ni asignarle una categoría. 


\section{Anthericum viruense Ravenna}

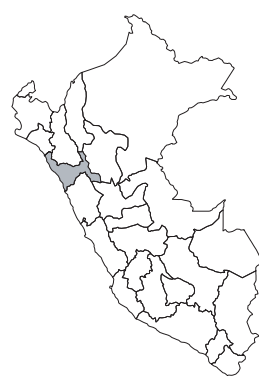

Publicación: Bol. Soc. Argent. Bot. 11: 146. 1967.

Colección tipo: N. Angulo 1111

Herbarios: HUT!.

Nombre común: Desconocido.

Registro departamental: LL.

Regiones Ecológicas: DST; $420 \mathrm{~m}$.

SINANPE: Sin registro.

Herbarios peruanos: HUT (holotipo).

Observaciones: Este taxón fue considerado por Brako \& Zarucchi (1993) como un endemismo; sin embargo, no ha sido posible evaluarlo, ni asignarle una categoría.

\section{Anthericum weberbaueri Poelln.}

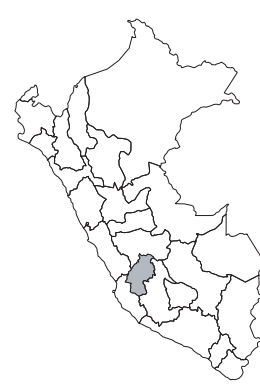

Publicación: Revista Sudamer. Bot. 7: 103. 1942.

Colección tipo: A. Weberbauer 6481

Herbarios: B; MOL!.

Nombre común: Desconocido.

Registro departamental: HV.

Regiones Ecológicas: MA; 2300—2400 $\mathrm{m}$.

SINANPE: Sin registro.

Herbarios peruanos: MOL (isotipo).

Observaciones: Esta especie herbácea no fue incluida en el catálogo de la flora peruana (Brako \& Zarucchi, 1993). Se conoce solamente de la cuenca del río Mantaro. El ejemplar tipo fue recolectado en 1913. No ha sido posible evaluarla, ni asignarle una categoría.

\section{Diamena stenantha (Ravenna) Ravenna}

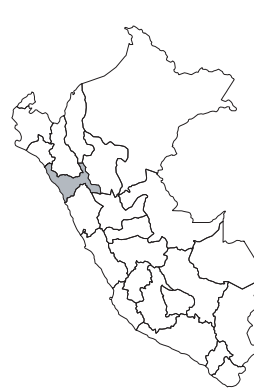

\section{CR, B1ab(iii)}

Publicación: Opera Bot. 92: 188. 1987.

Colección tipo: N. Angulo s.n.

Herbarios: $\mathrm{HUT}$.

Nombre común: Desconocido.

Registro departamental: LL.

Regiones Ecológicas: DST; altitud desconocida.

SINANPE: Sin registro.

Herbarios peruanos: HUT (holotipo).

Observaciones: Esta especie es la única representante de este género endémico al Perú. Ravenna (1977) consideró esta especie En Peligro Crítico, por conocérsela de una sola localidad, sin protección oficial, por ser palatable al ganado caprino en la zona y por la facilidad de remoción en su hábitat. Al parecer, restringida a la localidad original, amenazas a sus poblaciones están además, asociadas a modificación de su hábitat por expansión urbana.

\section{Diora cajamarcaensis (Poelln.) Ravenna}

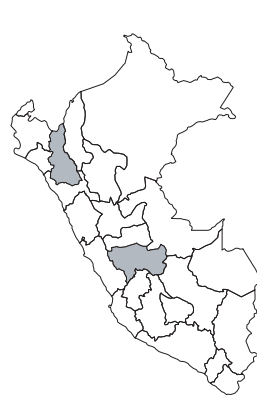

DD

Publicación: Opera Bot. 92: 191. 1987.

Colección tipo: A. Raimondi 6955

Herbarios: B; USM!.

Nombre común: Desconocido.

Registro departamental: CA, JU.

Regiones Ecológicas: MA; $2300 \mathrm{~m}$.

SINANPE: Sin registro.

Herbarios peruanos: USM (holotipo).
Observaciones: Esta hierba bulbífera fue descrita de una planta recolectada en 1874, probablemente del suroeste de Cajamarca, en la cuenca del Saña. Esta especie es la única representante de este género endémico al Perú. En Brako \& Zarucchi (1993) indicaron el comentario de Ravenna cuestionando la altitud atribuida al tipo, puesto que él la colectó en Junín a altitudes muy por encima de la considerada. Sin embargo, aquí se mantienen los datos originales de Raimondi. Esta especie requiere ser evaluada en sus aspectos taxonómicos y en el campo.

\section{Nothoscordum demissum Ravenna}

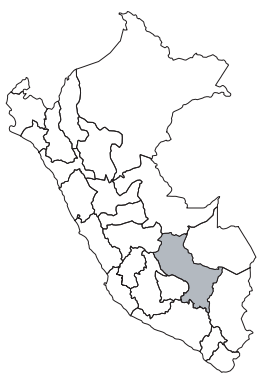

Publicación: Onira 3(1): 2. 1990.

Colección tipo: P.F. Ravenna 2820

Herbarios: Hb. Ravenna, K.

Nombre común: Desconocido.

Registro departamental: CU.

Regiones Ecológicas: Sin datos; altitud desconocida.

SINANPE: Sin registro.

Herbarios peruanos: Ninguno.

Observaciones: Hierba conocida, al parecer, de la colección tipo, una planta en cultivo, recolectada originalmente en la cuenca del Urubamba. No ha sido posible evaluarla, ni asignarle una categoría.

\section{Trichlora peruviana Baker}

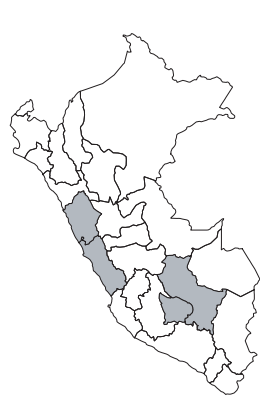

LC

Publicación: Hooker's Icon. Pl. 13: 29, t. 1237. 1877.

Colección tipo: C. Sandeman 5474

Herbarios: K.

Nombre común: Desconocido.

Registro departamental: AN, AP, CU, LI.

Regiones Ecológicas: MA, PSH; 2700$3900 \mathrm{~m}$.

SINANPE: PNH

Herbarios peruanos: USM (11).

Observaciones: Hierba bulbígera, conocida de varias localidades, tanto en la vertiente del Pacífico,como en valles interandinos, como el del Apurímac. Esta es una de las dos especies conocidas en este género endémico.

\section{Trichlora sandwithii Vargas C.}

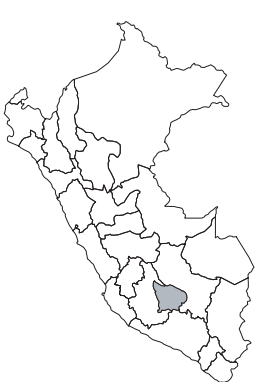

\section{DD}

Publicación: Biota 8(61): 35. 1969.

Colección tipo: C. Vargas C. 8748

Herbarios: CUZ!

Nombre común: Desconocido.

Registro departamental: AP.

Regiones Ecológicas: MA; 2700—3010 m.

SINANPE: Sin registro.

Herbarios peruanos: CUZ (holotipo+1).

Observaciones: Hierba bulbígera conocida, al parecer, de colecciones realizadas en 1941 y 1950, en la cuenca del Pampas. Esta especie habita ambientes intervenidos por la agricultura, asociada a cercos de chacras. Esta es una de dos especies conocidas en este género endémico al Perú. 